\title{
Contributions of Bird Studies to Biology
}

\author{
Masakazu Konishi, Stephen T. Emlen, Robert E. Ricklefs, \\ JOHN C. WINGFIELD
}

\begin{abstract}
Birds are widely distributed, highly diversified, and exhibit behavior and social organizations equal in complexity to mammals, yet they are generally more conspicuous and approachable in natural environments. These attributes make birds excellent subjects in many areas of biological research. The topics in which studies on birds have figured prominently include the mechanisms of species formation, the regulation of the distribution and abundance of animals, the effects of the environment on behavior and physiology, the biological and evolutionary significance of variations in social organizations, the encoding of information in animal communication, the sensory basis for migration and navigation, the effects of hormones on nerve cells and behavior, the ontogeny of brain and behavior, and the structure and function of the vertebrate brain. The outstanding record of avian research suggests that birds will continue to provide important models for developing and testing new ideas in various fields of biology.
\end{abstract}

$\mathrm{E}$ ACH TAXON PRESENTS TWO FACES: ONE OF UNIFORMITY that embodies the common features shared by all members of the group and the other of diversity that expresses the ecological and evolutionary responses of individuals and populations to the array of environments on Earth. When compared to vertebrate classes and invertebrate taxa of similar rank, birds are remarkable for their uniformity of anatomy, physiology, and life cycle. Penguins, flycatchers, geese, sparrows, and hawks resemble each other much more closely than their mammalian ecological counterparts (for example, seals, bats, sheep, mice, and cats). All birds lay eggs, most have extended parental care, and most enjoy relatively long lives, even compared to mammals. Yet, despite their uniformity, birds inhabit all regions of the earth and assume a wide variety of ecological roles.

We know the species-level taxonomy and geographical distribution of birds better than that of any other taxon of comparable diversity. Birds also show tremendous diversity in their social systems, making them valuable models for understanding the population biology and social behavior of other animal groups such as

M. Konishi is the Bing Professor of Behavioral Biology, Division of Biology, Californi Institute of Technology, Pasadena, CA $91125 . \mathrm{S}$. T. Emlen is Professor of Animal Behavior, Section of Neurobiology and Behavior, Cornell University, Ithaca, NY 14853. R. E. Ricklefs is Professor of Biology, Department of Biology, University of Pennsylvania, Philadelphia, PA 19104. J. C. Wingfield is Professor of Zoology, Department of Zoology, University of Washington, Seattle, WA 98195 primates. Most birds explore their environments and communicate with one another by the same senses of sight and hearing that we use. These sense organs, and the brain areas devoted to these senses, are highly developed in birds, making avian subjects ideal for the study of neural design and function.

Birds are active by day and generally conspicuous. One can attach markers or leg bands for individual recognition and follow individuals on their daily rounds of activity and over their lifetimes. Like butterflies and a few other groups noted for their beauty, birds have won the devotion of dedicated amateurs and thereby stimulated the amassing of a formidable database on life history attributes (birthrate, age at first reproduction, life span, and so forth) and populations from all parts of the world. In a volume on the lifetime reproductive success of animals (1), 13 of 25 nontheoretical chapters were drawn from studies of birds. The Zoological Record for 1985 indexed over 9300 articles on birds (excluding work on domesticated forms), slightly more articles than there are species. In the journal Ecology, $11 \%$ of articles published in 1987 and 1988 concerned avian studies, while in the journal Animal Behaviour, 37\% of articles published in the same 2 years dealt with birds.

All these attributes make birds ideal subjects for investigation in various fields of biology. In this article, we shall discuss how the study of birds has contributed to important discoveries in biology and to the formation and testing of significant new ideas in selected fields of biology.

\section{Evolution, Ecology, and Sociobiology}

Speciation. Ornithologists pioneered the study of the formation of species. Details of morphological variation and geographical distribution gleaned from field studies and museum collections led Mayr to conclude that the splitting of one species into two is usually preceded by a period of geographical isolation during which genetic differences accumulated (2). This idea, known as the theory of allopatric speciation, has stimulated many theoretical, empirical, and experimental studies of speciation. The ease of observing and capturing birds in the wild has also helped investigators to collect the best information on the heritability (3) and responses to selection of morphological traits in natural settings (4). Although birds have proved favorable subjects for the study of speciation, they have not figured so prominently as other groups in the study of evolution at higher phyletic levels. Nevertheless, birds have been subjected to the most ambitious molecular analysis of phylogeny of any taxonomic group, which, along with more traditional data, has allowed researchers to obtain a better understanding of avian historical biogeography and diversification (5).

Population and community ecology. Bird studies have had their greatest impact in the area of population and community ecology. 
For three decades beginning in the $1940 \mathrm{~s}$, the strongest and most influential voice for these new ideas was that of Lack (6). Lack visualized connections between the theory of interacting populations, developed by Lotka and Gause in the 1920s and 1930s (7), and patterns of morphological (8) and ecological (9) diversification among species; he also championed the position that populations are regulated by factors that have effects which intensify at higher density (10). He also initiated the field of evolutionary ecology (8), which sceks to interpret behavior and life-history attributes in the context of evolutionary optimization. Among Lack's most important insights was that ccological and geographical distributions of birds could be interpreted as the outcome of interspecific interactions (11). This insight expressed itself early in Lack's analysis of evolutionary diversification of Darwin's finches on the Galapagos Archipelago (8).

The principle of ecological divergence or resource partitioning mediated by competition became the basis of Hutchinson's (12) concept of the multidimensional niche, in which species compete and diversify with respect to many environmental factors, and that of limiting similarity set by interspecific competition. This concept quickly emerged, largely through a series of papers on birds by MacArthur (13), into a paradigm of community structure regulated by competitive interaction. Birds were also the subjects of 17 of 50 studies, summarized by Schoener (14), that quantified resource partitioning in terrestrial animal communities. Although the momentum of this paradigm sent much of community ecology onto an unproductive sidetrack during the 1970 s (15), it has provided a rich empirical base of data on community structure, and the controversy it generated greatly clarified thinking in the 1980s.

An important paradigm to emerge from the principles of population and community ecology was MacArthur and Wilson's (16) "equilibrium" theory of island biogeography, which related the number of species on islands to diversity-specific rates of immigration and extinction. Because their distributions on islands are so well known, birds have figured prominently in testing the theory (17), as well as applying it to the optimal design of nature reserves, which are, all too often, islands of habitat (18). Somewhat ironically, articles on avian biogeography affirming the connection between competition and coexistence raised questions in many minds about the statistical validity of community patterns and caused substantial rethinking of the competition paradigm (19).

Another of Lack's inspirations was the idea that natural selection adjusts life history traits in order to maximize fitness of the individual. Lack ( 8 ) initially applied this thinking to clutch size--the number of eggs laid per nest--in birds, but later (20) broadened his scope to include other attributes, including mating system and social behavior. Wynne-Edwards, drawing on his lifelong experiences with scabirds, disagreed with Lack by concluding that most life history traits, including social behavior, had evolved to regulate population numbers at levels that the environment could sustain (21). This debate over the units of selection (individuals versus populations) sparked a widespread reexamination of "species level" thinking in the 1950s and early 1960s, and led to the realization that selection at the level of groups could only occur under very restrictive conditions (22). Experiments involving the artificial alteration of clutch sizes and the measurement of resulting fledging success provided strong support for the theory of individual selection (23).

The early ideas and studies of Lack and others stimulated many serious long-term studies of life history traits and the adaptive significance of behavior. These investigations resulted in a considerable elaboration of optimization theory in studies of life histories (24) and foraging tactics (25). Birds have provided most of the empirical and experimental tests of optimal foraging theory, whether it addresses the choice of prey within foraging locality, the choice of switching to a new location as prey are locally depleted, or the avoidance of unpredictable supplies of food (25). Birds have also proven to be suitable experimental subjects for studies of life history evolution (26).

Behavioral ecology. Bird studies have also been important in forging new interdisciplinary bridges between animal behavior and ecology. In 1964, Crook (27) published a monograph on the comparative ecology and social organization of nearly 50 species of weaverbirds. He concluded that ecological factors are important in shaping the form of their societies. The degree of gregariousness, the presence or absence of territorial defense, and even the basic form of the mating system are all profoundly influenced by the abundance and the spatial and temporal distribution of key resources, predators, and competitors.

Crook's ideas of the ecological shaping of social behavior gained unusually rapid and widespread acceptance. The reason, in part, was because of the extraordinary wealth of preexisting avian field data that had been accumulating in the literature since the turn of the century. Many ornithologists made immediate use of this abundance of information to verify Crook's correlational findings for other avian groups. Soon such analyses extended beyond ornithology, and parallel correlations between simple ecological predictors and social structure were uncovered in groups as diverse as coral reef fishes (28), anurans (29), bats (30), ungulates (31), and primates (32).

Comparative studies were soon supplemented by experimental ones, and descriptive explanations were replaced by analytical models. Brown (33) incorporated economic thinking into his models of adaptive behavior. In his theory of economic defendability, he argued that the distribution pattern of a resource determined the benefit-to-cost ratio of defending that resource, and he used this approach to model the evolution of territorial behavior (33). Studies of nectar-feeding birds, in which the caloric costs and benefits of territorial defense could be measured with accuracy, have provided strong support for the model (34).

Economic considerations are also pivotal to our understanding of why animals live in groups. Two ecological factors, predator avoidance and feeding efficiency, are believed to be primary determinants of grouping tendencies. Depending on the types of predators and abundance of predators, grouping may make individuals more conspicuous and thus more susceptible to predation. On the other hand, grouping may also provide the means for more efficient predator detection and deterrence (for example, through sentinel behavior or group mobbing). Similarly, when food resources are not renewable and are spatially stable, grouping can lead to overexploitation of these resources. But, if food resources are ephemeral and unpredictable in location, group living can provide a means for enhanced food localization (for example, through the pooling of information gathered by multiple foragers). These types of costbenefit trade-offs determine when grouping is advantageous, as well as the optimal group size. Avian examples have been fundamental in the development and testing of these ideas. Trained raptors have been used to quantify the benefit that prey species gain by living in flocks of different sizes (35). Colonial birds provide the best evidence to date for information pooling in the localization of unpredictable food sources (36).

Mating systems. Avian studies have been central to the development of mating system theory. Orians and his colleagues were the first to propose the adaptive significance of polygyny (one male pairing with more than one female) (37). They argued that polygynous mating occurs when resource distributions are sufficiently uneven that a female can maximize her chance of leaving offspring by mating bigamously with an already mated male on a high-quality territory rather than mating monogamously with an unmated male occupying a lower quality territory. This "polygyny threshold" 
model was based on years of research on blackbirds and wrens (38).

Emlen and Oring (39) later incorporated ideas of economic defendability with sexual selection theory to develop an ecological classification of avian mating systems. The reproductive output of males is limited by the availability of potential female partners, and males compete among themselves to gain access to receptive females. Ecological factors often determine the distribution, and hence the defendability, of female mates. Emlen and Oring suggested that polygyny occurs when individual males can control the access of other males to potential mates and thus can monopolize several females for themselves. Social and ecological variables that influence the mating options of individual organisms have proven to be strong predictors of mating systems, not only of birds, but also for many other animal groups including amphibians (29), insects (40), and mammals (41).

Traditionally, biologists have classified mating systems according to the pair bonds that form between individuals. Recent evidence indicates, however, that individuals of both sexes commonly engage in reproductive activities outside of the pair bond. Such "mixed mating strategies" (42) take the form of extra-pair copulations by both sexes and, among birds, of intraspecific nest parasitism by females. Studies of birds previously assumed to be monogamous have demonstrated a surprisingly high level of mixed paternity and maternity of clutches (43). The availability of DNA fingerprinting is giving ornithologists and other field biologists a new tool with which to investigate the basis of mate choice and the conditions under which individuals elect to mate with individuals other than their nominal partners.

Altruism and kinship. Bird studies have a key role in testing recent ideas of the importance of kinship in the evolution and maintenance of altruistic behaviors. The existence of such behaviors as restraint from reproduction by honey bee workers, alarm calling by social rodents, and helping at the nest by birds have long posed paradoxes for evolutionary biologists because they appear to contradict the basic self-interest fostered by natural selection. How can behaviors evolve if their performance is detrimental to the performer? Hamilton's (24) concept of inclusive fitness showed that altruistic behaviors could be favored by natural selection provided that they were directed toward genetic relatives, which have a high probability of
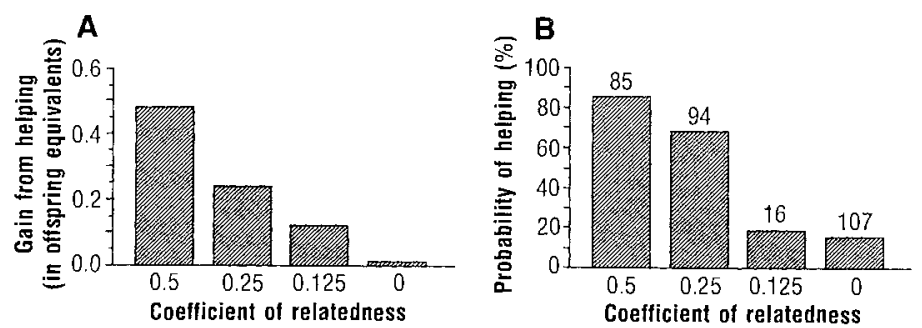

Fig. 1. The importance of kinship in explaining helping-at-the-nest behavior in a cooperatively breeding bird, the white-fronted bee-eater (Merops bullockoides). In this species, approximately $55 \%$ of all nonbreeding adults act as helpers; the remaining $45 \%$ do not. Birds that do help incubate eggs and defend and provision nestlings. (A) The indirect fitness gain (kin benefit) realized by a helper is plotted as a function of the helper's relatedness to the nestlings it aids. This gain is measured in offspring equivalents (48) and is calculated as the product of two terms: the average number of additional offspring successfully fledged as a result of a helper's activities, and the coefficient of relatedness between the nestlings and the helper (sibling $=0.5$, half-sibling $=0.25$, and so on). (B) The probability that a potential helper (a nonbreeding bee-eater with a recipient nest available) becomes an actual helper is plotted as a function of its coefficient of relatedness to the recipient nestlings. Numbers above histograms are sample sizes of potential helpers in each kin category. White-fronted bee-eaters are most likcly to become helpers when the recipients are close genetic relatives and, as a result, the kin benefits realized from helping are large. carrying the genes responsible for the behavior. Cooperatively breeding birds (birds in which extra adults assist the breeding pair in the rearing of young) have provided a test arena for Hamilton's theory, because the costs and benefits associated with helping behaviors can be accurately quantified (44).

Several long-term studies of cooperatively breeding birds provide data on the relative importance of kinship in helping (45-47). Helpers may benefit from their actions in two major (and additive) ways: they may reap kinship benefits by increasing the survival of nondescendant relatives; and, by helping in the present, they may increase their own prospects for becoming successful breeders in the future. Different species, depending on their ecology and demography, vary in the relative importance of the two types of benefits. White-fronted bee-eaters (Merops bullockoides) provide an example of kin favoritism and kin benefit (Fig. 1) $(46,48)$, whereas Florida scrub jays (Aphelocoma c. coerulescens) illustrate a case where the future direct (personal) benefits of helping are large (47).

\section{Ethology}

Communication. The study of communication is an important component of animal sociology, and birds have been favorite subjects in this field. The realization that displays and vocalizations of animals are their means of communication was the key to the development of ethology as a discipline. It is not coincidental that two of the founders of ethology, Lorenz (49) and Tinbergen (50), and even their predecessors, Heinroth (51) and Whitman (52), all studied birds. Comparative and experimental studies of signaling have developed side by side in this field. Lorenz's study of behavior in ducks and geese (53), Kortlandt's study of cormorant display (54), and the studies of various gulls by Tinbergen and his associates (55) are examples in which an understanding of the evolution of signaling behavior by comparing closely related species was attempted. Similarly, a comparative study of alarm calls among different bird species led Marler to the concept of evolutionary convergence in animal signals (56), whereas the diversity of bird songs led him to the concept of species specificity in animal signals that serve in species recognition (57).

Experimental studies of communication aim at elucidating the rules of encoding information and the function of signals. The methods for studying the coding rules involve the use of dummies and recorded and synthetic sounds. Consistent with the conclusion inferred from comparative studies, the results of experimental work show that birds use species-specific visual displays and vocalizations to recognize the members of their own species or geographical populations. Different bird species use different sets of acoustical cues to recognize the song of their own species. Any one of two or three cues appears to be sufficient for species recognition; there is redundancy in the encoding of species specificity in song (58). Birds can also use individual variations in song and calls for recognition of neighbors, mates, and family members (59). The generalizations drawn from comparative and experimental studies of acoustic communication in birds have not only contributed to our knowledge of animal communication, but also have guided the study of vocal communication in other animals, including primates $(60)$.

Ontogeny and learning. Studies of bird song led to important advances in understanding the processes of behavioral ontogeny and the factors that control them (61). Early bird fanciers knew that young birds must have a good tutor to become a good singer. They also knew that birds could be bred for more elaborate song, as in the domestic canary. Thus, differences in song between species and between individuals contain both heritable and experiential components. The experiential component has been most extensively stud- 
ied since the seminal work of Thorpe (62).

Learning of voice, whether it occurs in human or avian babies, involves translation of the auditory percept of the voice into motor coordinations that give rise to the same voice, that is, the sound that causes the same auditory percept. Song learning consists of perceptual and sensorimotor phases. Young birds commit a tutor song to memory in the first phase and reproduce the memorized song in the second. The perceptual phase may be restricted to a relatively short period in early life or it may be extended, the details varying according to such factors as the photoperiod and the conditions under which song tutoring occurs. Given a choice between the species' own song and alien songs, young birds learn the song of their own species. In the sensorimotor phase, birds must hear themselves sing in order to reproduce the memorized song. Birds deafened after the perceptual phase, but before or during the sensorimotor phase, cannot reproduce the memorized song (63).

Birds are the only known nonhuman animal that learns complex vocalizations (64). The characteristics of song learning have intriguing resemblances to those of speech acquisition in human infants (65). Speech sounds are particularly attractive to human babies. Infants can discriminate between different speech sound categories even in languages they have never heard (66). The babbling stage of speech development resembles an early stage of bird song development. The impressionable phase of speech acquisition and the need for auditory feedback in human speech development also parallel the major features of song development in birds. Because intrusive experiments cannot be performed on humans, avian song learning is a valuable animal model of speech acquisition.

Orientation and navigation. Orientation and navigation is another field in which the nature and function of sensory cues are the subject of investigation. Birds are the champions of long-distance travel. Hundreds of species make annual migrations of thousands of kilometers, returning with remarkable precision to the same several square kilometers of territory on both their breeding and their wintering grounds.

Much of our current knowledge about the mechanisms of animal orientation comes from experimental work with bees (67), fish (68), and birds (69). The routes, destinations, and timing of migration are, however, better known for birds than for any other animal. Investigators can follow navigating birds for long distances by airplanes and radar. Birds also can be made to carry various devices (for example, radio transmitters, miniature cameras, bar magnets, and vision-impeding spectacles). Migrants can be tested in specially designed cages for their orientation response to natural and artificial stimuli (70).

We now know that migratory birds can make use of several different cue systems for determining the compass directions of their migratory flights. The position of the sun by day, polarized light patterns at sunset, and the configurations of the stars at night all serve as celestrial cues (71). The earth's magnetic field may also provide directional information (72). Migrants have proven to be good meteorologists as well. They time their departures to catch favorable tail winds aloft, and they often adjust their flight headings to (at least partially) compensate for the drift that occurs when they encounter crosswinds $(73,74)$. One key finding to emerge from these studies is that birds have considerable redundancy in their orientation systems. If one cue is temporarily unavailable or provides unreliable information, another cue can be used in its place. Although the existence of such redundant "backups" makes good adaptive sense, it has been difficult to design experiments that can sort out the roles of different cues. Redundancy has also raised stimulating new questions: Does the simultaneous use of multiple cues result in increased accuracy of orientation? Does a hierarchy exist in the relative importance of different types of information?
How does each cue system become integrated with or calibrated against the others $(74,75)$ ?

Navigation researchers distinguish between a compass "sense," by which the animal orients in a particular direction and maintains that course, and a map "sense," by which the animal determines its position relative to some reference location (usually home). Many species of migratory birds may require only a compass ability; other migrants and homing pigeons use a map sense as well. Whereas several compass cues have been studied in detail, the map sense remains poorly understood. Current information indicates that celestial cues do not provide map information (76). Models based on olfactory (77) and magnetic $(75,78)$ cues have been advanced, but need more testing. Solving the map riddle remains the major challenge for orientation researchers.

\section{The Interfaces of Physiology, Ecology, and Behavior}

Physiological adaptations. Birds as experimental subjects have been important in linking pure regulatory physiology to ecology and behavior. There are many good examples of physiological and behavioral adaptations to the environment. Schmidt-Nielsen (79) and Scheid (80) showed that the avian lung is unique in being a rigid structure through which air flows in a one-way system regulated by a complex network of air sacs. The result is a remarkably efficient system for oxygen uptake and loss of carbon dioxide, especially for flight, as indicated by the study of birds flying in wind tunnels to simulate the behavior under natural conditions (81). Studies have been carried out on such topics as the ability to control body temperature in extremely hot and cold climates for life in deserts and high altitudes and latitudes (82), nasal salt glands for secretion of excess sodium chloride in marine and arid environments (83), and kidneys that minimize water loss by excreting uric acid (84). These studies paved the way for a generation of avian physiological ecologists who, together with investigators of other vertebrate groups, have advanced our knowledge of how organisms maintain homeostasis in environments as diverse as the poles, deserts, oceans, and rain forests.

Adaptation to the environment requires compromise among competing demands for time and energy allocated to different functions (85). Studies of avian reproduction, particularly during the periods of incubating the eggs and caring for young, have elucidated the role of environmental and physiological constraints on nestling development and parental care (86-88). In particular, growth rate strikes a balance between rapid growth for avoidance of predation and slower growth requiring less energy and nutrients (20). Some birds hatch as self-sufficient chicks and others as helpless nestlings, and there are intermediates between these types. These differences show how the rate of growth of the chick is adjusted to allocation of the parent's time between foraging and direct care (86, 89). Behavioral studies also revealed the role of food solicitation in regulating parental feeding (90), adding sibling competition and parent-offspring conflict to the list of factors that interact to mold avian reproductive patterns (91).

Hormones and social behavior. The concept of hormonal regulation of behavior was developed in part by many studies on birds during the period between the 1930 s and the 1960 s $(92,93)$. A combination of sociobiological and physiological approaches is now adding a new dimension to the study of social behavior. The classical investigations of Lehrman (94) and Hinde (95) showed that behavior of one individual affects hormone secretion in another with both intra- and intersexual effects. Early investigators assessed hormone secretion indirectly by noting hormone-controlled behavior, or by 
measuring the state of the gonads and secondary sex characters. With the advent of increasingly sensitive radioimmunoassay techniques for measuring hormone levels in the blood, marked birds can be caught repeatedly with minimum disturbance to collect a small amount of blood for hormone titration. During aggressive interactions over territory or mates, plasma levels of testosterone increase, especially in monogamous species (Fig. 2) (96). Testosterone elevates and enhances the expression of territorial aggression but at the same time inhibits male parental behavior $(97,98)$. Thus, monogamous species in which males feed young have high testosterone for a very short period in early spring, whereas polygynous species in which males tend not to feed young remain very aggressive and have high testosterone for prolonged periods during the breeding season (98). If a "polygynous-like" seasonal profile of testosterone levels is induced in monogamous males, these males also tend to become polygynous (98). Such studies offer physiological explanations for social behavior and, by the use of hormone agonists and antagonists to manipulate behavior, provide new tools for field investigations in sociobiology and behavioral ecology.

Hormones and seasonal behavior. Over 60 years ago, Rowan (99) discovered that the annual cycle of daylength exerted a regulatory effect on gonadal development and migratory behavior in birds. When he exposed captive male dark-eyed juncos (Junco hyemalis) to long days in midwinter, they began to show migratory and reproductive behavior, and also testicular development. These discoveries led to a growing field of research on environmental control of reproduction and associated events in all vertebrate groups. For example, King and Farner (100) published a series of seminal papers on the regulation of lipid deposition during bird migration. Many others demonstrated a role for changing daylength in the regulation of breeding seasons in over 60 avian species (101). Fewer investigations, however, have tackled the neuroendocrine mechanisms by which photoperiod is perceived and transduced into hormone secretion that in turn regulates reproductive development and associated behaviors.

In a now classic experiment, Follett, Mattocks, and Farner (102) showed that exposure of male white-crowned sparrows (Zonotrichia leucophrys) to an 8-hour pulse of light given at intervals after the last dawn resulted in a pronounced increase in secretion of luteinizing hormone (one of the gonadotropins associated with reproductive development). This increase occurred, however, only when the light pulse fell within the photosensitive phase of a circadian rhythm, which was between about 12 and 18 hours after dawn. Their experiment remains one of the most convincing demonstrations of an endogenous rhythm of photosensitivity, first postulated by Bünning (103). Curiously the photoreceptors by which birds

Fig. 2. Plasma levels of testosterone in free-living male song sparrows (Melospiza melodia) after removal of a territorial male. Replacements are those males that took over the vacant territory, and neighbors are those males with territories adjacent to the replacements. Controls were captured in a separate area in which territory boundaries were known to be stable. Histograms represent the means and vertical bars are the standard errors. Numbers within the histograms are the sample size. Replacements, $P<0.005$; neighbors, $P=0.001$. [Reprinted from (96) with permission, (C) 1985 Academic Press] measure daylength are not retinal (104), but lie within the brain (105). The use of fiber optics to illuminate specific areas of the brain has demonstrated that the photoreceptors are situated in the basal hypothalamus (106). In the past 30 years, the role of light as a timing cue for endogenous circannual rhythms has also gained acceptance through research on birds (107). Additionally, a state of refractoriness was found in which organisms exposed to a stimulatory photoperiod eventually become insensitive to that stimulus. This process is crucial for the termination of reproductive function and prevents further breeding at times when environmental conditions for survival of young become unfavorable. The mechanisms of refractoriness to light stimuli are still not clear and remain one of the major unsolved problems of reproductive biology (108).

\section{Neurobiology}

Hormones and brain. Bird studies have had a leading role in the development of neuroendocrinology. For example, Benoit and Assenmacher (109) showed that the hypothalamus of the mallard duck (Anas platyhynchos) exerted a profound regulatory role over secretions of the anterior pituitary gland. This discovery came at a time when the question of neuroendocrine secretion and regulation of pituitary function was a major controversy. The work of Oksche, and associates (110) on birds was significant in elucidating the morphology of the hypothalamo-pituitary unit. Developments in the isolation and sequencing of hypothalamic regulatory peptides in mammals were supplemented by similar work in birds in which several forms of single type of peptide were identified, suggesting that neuroendocrine regulation of pituitary function is more complex than was realized previously (111).

Steroid hormones act on target cells by regulating gene expression and protein synthesis (112). The avian oviduct secretes a special protein, ovalbumin, which makes up a major component of the egg white. O'Malley and his associates (113) were among the first to discover the advantages of the oviduct of chicks for the study of hormone-mediated protein synthesis. They showed that progesterone binds to intracellular receptors in the oviduct to form a steroidreceptor complex which, in turn, binds to the genome and stimulates transcription of the mRNA for ovalbumin. However, there are alternate pathways for the action of steroid hormones once they entered a cell. Hormones can be metabolized to an active form that binds to receptors or, as in birds, they may be converted to an inactive form like $5 \beta$-dihydrotestosterone, derived from testosterone (114). Whether this shunt mechanism is widespread in vertebrates remains to be seen.

The discovery of the song control system in the brain by Nottebohm and his associates (115) has provided a very useful preparation in which a direct link from hormones to brain and to behavior can be established. Songbirds have special brain areas for the control of song, whereas other birds, with the exception of parrots, lack such areas (116). Few vertebrate neural systems controlling particular behaviors form as discrete and readily identified groups of nuclei as the song system. Song is also a seasonal behavior, which is controlled by sex steroids. A subcutaneous implant of testosterone induces song in females, young birds, and males in nonbreeding conditions. This behavioral effect of testosterone is accompanied by rapid physiological and morphological changes in many parts of the song control system. For example, testosterone induces or increases protein synthesis in a song nucleus of female white-crowned sparrows within a few days after hormone implantation (117). Castration of male zebra finches (Poephila guttata) causes a decrease in the number of acetylcholine receptors in the muscles of their vocal organ and subsequent administration of testosterone 
restores both the number of the receptors and the activity of the enzymes involved in the synthesis and degradation of acetylcholine (118). In female canaries (Serinus canaria), both the length of dendrites of a certain class of neurons and the number of synapses in a song nucleus almost doubles in response to administration of testosterone (119).

Although these studies artificially manipulated hormone levels, similar changes occur naturally with the season. Plasma levels of testosterone and other sex steroids change seasonally (120). Nottebohm (121) discovered that the volume of one of the song nuclei of the male canary changes with the season. It is now known that similar changes occur in other song nuclei and other birds (122). These volume changes are partly due to changes in the ability of neurons to stain with thionin, which stains Nissl substance found in dendrites and perikarya (123). The seasonal volume fluctuations are, therefore, partly due to seasonal variations in the length of dendrites. Changes in dendrites and synapses indicate that the adult brain circuitry is not fixed, although such changes may not involve qualitative alterations in the existing neural circuits (124). The idea that the seasonal appearance and disappearance of song is accompanied by making and unmaking of neural connections may revolutionize our understanding of behavioral plasticity and learning (125)

In many species, the male sings and the female does not. This sexual dimorphism in behavior is correlated with gender differences in brain anatomy. The male song nuclei contain more neurons of larger size than the female counterparts (126). Also, connections between some of the nuclei are missing or rudimentary in the female (127). Such large brain gender differences were not known in any other animal. Subsequent searches have since revealed several cases of large gender differences in the mammalian central nervous system including humankind (128)

Brain development and neural plasticity. The song control system provides ideal materials for the study of the role of hormones in brain development. It was thought that gender differences in the brain arise because the sexually dimorphic areas of the female brain do not grow, whereas the homologous areas in the male grow under the influence of early gonadal steroids (129). In the zebra finch, the male and the female song nuclei are similar in early life. Neurons of the female forebrain song nuclei do not just fail to grow but undergo atrophy and death, whereas the male counterparts grow (127). The involvement of cell death in brain sexual differentiation is now known or suspected in most of the well-documented mammalian examples (130).

The causes of cell death and the conditions for cell survival are the focus of much current research in neuroscience. Most known cases of programmed neuronal death in which not just axons but cell bodies die occur in the spinal cord, ganglia, and the brain stem. The avian song system offers opportuniries for investigators to study neuronal death in the forebrain. In the zebra finch, an implant of estrogen in a newly hatched female masculinizes her song control system both by preventing neuronal death in her forebrain song nuclei and by promoting the development of connections between some of the nuclei (131). Although the mechanisms of estrogen action are not known in this case, the possibility to prevent programmed cell death by such a simple agent opens a new avenue of research in neuroscience.

The avian brain displays important similarities with the brains of fishes, amphibians, and reptiles. Growth and regeneration of organs in adult animals are well known among these animals. In birds, for example, new neurons are born in the adult forebrain, and some of them become incorporated in functional circuits including the song system. These new neurons migrate from their birthplace to their destinations closely attached to radial glial cells (132). Radial glia are present in the adult brain among birds and lower vertebrates, whereas these cells disappear in mammals after they guide neuronal migration during the development of the brain. Studies show that new inner ear hair cells grow to replace injured ones in young birds (133). The identification of the conditions necessary for regeneration and adult retention of embryonic attributes will help to understand why mammals lack these properties.

Brain structure and function. Because the forebrains of nonmammalian vertebrates lack the layered structure typical of the mammalian neocortex, it was long assumed that nonmammalian vertebrates do not have a neocortex. The large tissue mass on the surface of the forebrains of birds and some reptiles was thought to be homologous to the striatum of mammals, which is a subcortical structure. Karten (134) reexamined this view by studying the projections of the auditory and visual systems to the forebrain in the pigeon and found that the striatal tissue mass contains large thalamic receiving areas as in the mammalian neocortex. This work led him to a revolutionary theory that areas homologous to the neocortex are present in the brain of nonmammalian vertebrates, but that they form aggregates instead of layers. This theory has provided a possible solution to one of the persistent puzzles in comparative neuroanatomy, that is, the evolution of the neocortex.

The brains of different animals exploit similar design principles in differing degrees. Animals adapted for extreme conditions or special niches are likely to push certain design principles more than other species. Such "specialists" abound among birds. For example, barn owls (Tyto alba) can localize small rodents in total darkness by listening to the rustling sounds they make (135). The brain mechanisms of sound localization are better understood in this species than in any other vertebrate (136). The nucleus laminaris is a third-order auditory station in the avian brain and thought to be homologous to the medial superior olivary nucleus of mammals. In unspecialized species such as chickens and pigeons, the nucleus laminaris consists of a monolayer of neurons, which form circuits for the measurement of interaural time differences (137). In the barn owl, this nucleus is

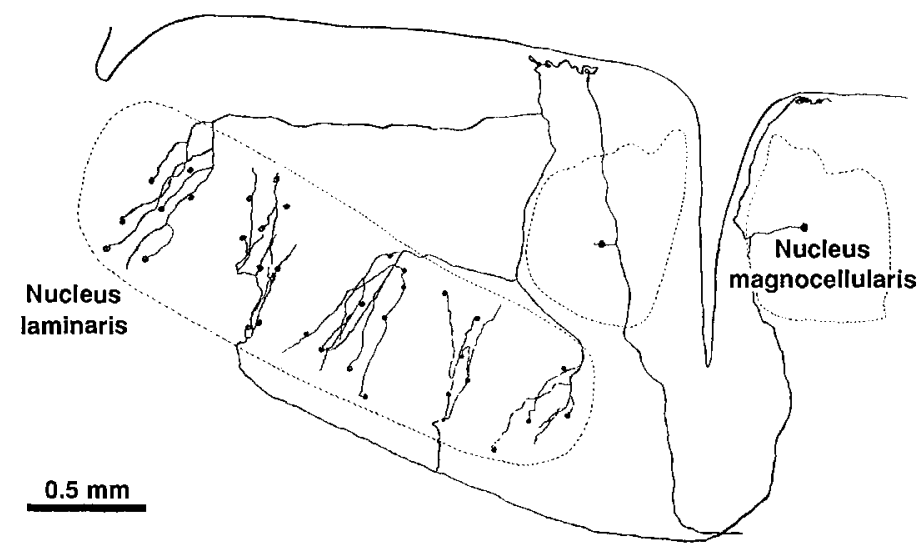

Fig. 3. Axonal delay lines for measurement of interaural time differences in the barn owl's brainstem. Shown is the innervation of the nucleus laminaris by two typical axons of the magnocellur cochlear nucleus, an ipsilateral one arriving from the dorsal side (top of the figure) and a contralateral one from the ventral side after crossing the midline of the medulla. These fibers branch out and course across the nucleus laminaris to the side opposite to the side of their entry. As the ipsilateral and contralateral fibers interdigitate, they innervate laminaris neurons, shown by small circles. Conduction time of nerve impulses in these fibers varies systematically as a function of distance from the point of their entry to the nucleus laminaris. Thus, for example, laminaris neurons located near the dorsal side receive impulses from the ipsilateral cochlear nucleus earlier than those from the contralateral nucleus. The nucleus laminaris uses this asymmetry in conduction time for measurement of interaural time differences in the microsecond range. [Reprinted from $(138)]$ 
hypertrophied and the neural circuits are more elaborate, although they use the same principles of operation as the monolayer version (Fig. 3). The neural circuits for time measurement contain binaural coincidence detector neurons and axonal delay lines (138). The coincidence detectors fire maximally when nerve impulses arrive simultaneously from the right and left sides. When the axonal paths to these neurons from the ears are equal, nerve impulses starting simultaneously from the two ears reach the coincidence detectors at the same time. These coincidence detectors fire maximally when sound reaches the two ears simultaneously. Other coincidence detectors fire maximally only when sound reaches one ear later than the other ear by a particular delay, because the axonal paths to them from the two sides are unequal. Physiological evidence suggests similar circuits in the medial superior olivary nucleus, but they have yet to be identified (139).

Mapping of the external sensory world in the brain is another design principle that is used by widely different animals. The cortical maps of the retina, the inner ear, and the body surface are well known. These maps are due to topographical projections of the sensory epithelia. Since the inner ear, unlike the retina, does not register the location of stimuli, it was thought unlikely that the auditory system uses a map-like representation of space. Such a map was, however, discovered in the barn owl's midbrain in which each neuron responds maximally only to sound coming from a restricted area in space $(140)$. The space-specific response of these neurons is a result of processing within the brain. Thus, the auditory space map of the owl led to the concept of centrally synthesized or computational maps (141). A subsequent study revealed a crude map of auditory space in the superior colliculus of the cat (142). The auditory space map of the owl projects topographically to the tectum, in which it forms a joint auditory-visual map of space (143). This and other findings indicate that computational and projectional maps are functionally equivalent. Therefore, it follows that all maps are made for information processing and encoding and are not the simple consequence of embryological and anatomical design requirements.

\section{Concluding Remarks}

Biologists can take advantage of the diversity of life by using special animals, organs, behavior, and social systems to gain insights into general principles. Birds have ranked high in offering particularly useful models. Avian research has been pivotal to the development of subdisciplines of organismal biology such as ecology, sociobiology, and ethology. Neurobiology, including developmental neurobiology, neuroendocrinology, neuroethology, and comparative neuroanatomy, has also derived benefit from bird studies. Research on birds should continue to be important in the future development of biology. For example, bird studies with hormone radioimmunoassay will have a profound impact on our methods of studying social behavior. Long-term studies of avian societies, combined with molecular techniques for assigning parentage, will help clarify the evolutionary significance of different mating strategies and patterns of parental care. Premigratory fattening in songbirds and prefledging loss of fat in petrels could provide useful models for studying control of appetite and problems of obesity. Gerontologists might profit from investigating the general delay of the onset of physiological aging in birds. The study of avian brains seems also destined to produce more discoveries of general importance, in particular concerning the proliferation of brain cells throughout the individual's life. Avian contributions to biology extend far beyond the selected topics covered in this article and will continue to be important in many areas of biological research.

\section{REFERENCES AND NOTES}

1. T. H. Clutton-Brock, Ed., Reproductive Success (Univ, of Chicago Press, Chicago, IL, 1988)

2. E. Mayr, Systematics and the Origin of Species (Columbia Univ. Press, New York, 1942).

3. F. Cooke and P. A. Buckley, Eds., Avian Geretics (Academic Press, Orlando, FL, 1987).

$\rightarrow$ P. T. Boag and P. R. Grant, science $214,82(19 \rightarrow$ T. D. Price, P. R. Grant, H. L. Gibbs, P. T. Boag, Nature 309, 787 (1984).

$\rightarrow$ C. G. Sibley, J. E. Ahlquist, B. L. Munroe, Jr., Auk 105, 409 (1988).

6. S. E. Kingsland, Modeling Nature: Episodes in the History of Population Ecology (Univ. of Chicago Press, Chicago, IL, 1985); J. Sheail, Seventy-Five Years in Ecology, The British Ecological Society (Blackwell, Oxford, 1987).

7. A. Lotka, Elements of Physical Biology (William \& Wilkins, Baltimore, MD, 1925); G. F. Gause, The Struggle for Existence (William \& Wilkins, Baltimore, MD, 1934). 8. D. Lack, Danwin's Finches (Cambridge Univ. Press, New York, 1947).

9. —_, Ecological Isolation in Birds (Harvard Univ. Press, Cambridge, MA, 1971). 1954). The Natural Regulation of Animal Numbers (Oxford Univ. Press, London,

11. D. Lack, Ecological Adaptations for Breeding in Birds (Methuen, London, 1968).

12. G. E. Hutchinson, Cold Spring Harbor Symp. Quant. Biol. 22, 415 (1957).

13. R. H. MacArthur and R. Levine, Am. Nat. 101, 377 (1967).

14. T. W. Schoener, Science 185, 27 (1974).

15. D. Simberloff, Symthese $\mathbf{4 3}$ (no. 3), 79 (1980); in Perspectives in Omithology, A. H. Brush and G. A. Clark, Jr., Eds. (Cambridge Univ. Press, New York, 1983), pp. 411-455; J. Wiens, ibid, pp. 355-403; D. R. Strong, Jr., L. A. Szyska, D. S Simberloff, Evolution 33, 897 (1979).

16. R. H. MacArthur and E. O. Wilson, The Theory of Island Biogeography (Princeton Univ. Press, Princeton, NJ, 1967); Evolution 17, 373 (1963).

$\rightarrow$ M. E. Gilpin and J. M. Diamond, Oecologia 52,75 $(19 \varepsilon \rightarrow$ D. Simberloff, Annu. Rev. Ecol. Syst. 5, 161 (1974).

$\rightarrow$ J. M. Diamond, Biol. Conserv. 7, 129 (1975); Science 193, 1027 (1976); J. Terborgh, ibid., p. 1029.

19. J. M. Diamond and M. E. Gilpin, Oecologia 64, 75 (1982); E. F. Conner and D. Simberloff, Ecology 60, 1132 (1978).

$\rightarrow$ G. Hardin, Science 131, $1292(1960)$

21. V. C. Wynne-Edwards, Animal Dispersion in Relation to Social Behaviour (Oliver and Boyd, Edinburgh, Scotland, 1962).

22. G. C. Williams, Adaptation and Natural Selection (Princeton Univ. Press, Princeton, NJ, 1966).

23. D. Lack, Poptuation Studies of Birds (Clarendon Press, Oxford, $19 t \rightarrow$ C. M Perrins, J. Anim. Ecol 34, $601(19 \rightarrow$ T. E. Martin, Anmu. Rev. Ecol. Syst. 18, 453 (1987).

$\rightarrow$ W. D. Hamilton, J. Theor. Biol. 7, l (1964); S. C. Stearns, Q. Rev. Biol. 51, 3 $\left(19^{\prime} \rightarrow\right.$ W. M. Schaffer, Ecology 55, 291 (1974).

25. J. R. Krebs and R. H. McCleery, in Behavioural Ecology, J. R. Krebs and N. D. Davies, Eds. (Sinauer, Sunderland, MA, 1984), pp. 91-121; D. W. Stevens and J. R. Krebs, Foraging Theory (Princeton Univ. Press, Princeton, NJ, 1986).

26. N. Nur, Evolution 43, 351 ( $191 \rightarrow$ D. Reznick, Oikos 44, 257 (1985).

27. J. H. Crook, Behaviour (Suppl.) 10, 1 (1964)

28. E. S. Reese, Z. Tierpsychol. 37, 37 (1975); P. F. Sale, in Contrasts in Behavior: Adaptation in the Aquatic and Terrestrial Environments, E. S. Reese and F. J. Lighter Eds. (Wiley, New York, 1987), pp. 313-346.

$\rightarrow$ D. Wells, Anim. Behav. 25, 666 (1977)

30. J. W. Bradbury and S. L. Vehrencamp, Behav. Ecol. Sociobiol. 1, 383 (1977); ibid., 2, 1 (1977)

$\rightarrow$ P. J. Jarman, Behaviour 48, 215 (1974).

32. J. H. Crook and J. S. Gartlan, Nature 210, 1200 (1966); T. H. Clutton-Brock and P. H. Harvey, J. Zool (Lond.) 183, 1 (1977)

$\rightarrow$ J. L. Brown, Wilson Bull. 76, 160 (1964).

34. F. L. Carpenter and F. E. MacMillen, Science $194,639\left(19^{\prime} \rightarrow\right.$ F. B. Gill and L. L. Wolf, Ecology 56, 333 (1975); A. Kondric-Brown and J. Brown, ibid 59, 285 (1978); P. W. Ewald and G. H. Orians, Behav. Ecol. Sociobiol. 12, 95 (1983).

35. R. E. Kenward, J. Anim. Ecol. 47, 449 (1978).

$\rightarrow$ P. Ward and A. Zahavi, Ibis 115, 517 (1973); C. R. Brown, Science 234, 83 $(19\{\rightarrow$ C. H. Brown, Ecology 69, 602 (1988); E. Greene, Nature 329, 239 (1982).

37. G. H. Orians, Am. Nat. 103, 589 (1969)

$\rightarrow$ Ecol. Monogr. 31, $285(19 \mathrm{C} \rightarrow \mathrm{J}$. Verner, Evolution 18, $252(1964)$; Verner and M. F. Willson, Ecolog $47,143(19 \rightarrow$ M. F. Willson, Ecol. Monogr. $36,51(1966)$.

39. S. T. Emlen and L. W. Oring, Science 197, 215 (1977).

40. R. Thornhill and J. Alcock, The Evolution of Insect Mating Systems (Harvard Univ. Press, Cambridge, MA, 1983).

41. D. I. Rubenstein and R. W. Wrangham, Ecological Aspects of Social Evolution (Princeton Univ. Press, Princeton, NJ, 1986).

42. R. L. Trivers, in Sexual Selection and the Descent of Man, B. Campbell, Ed. (Aldine, Chicago, IL, 1972).

43. F. McKinney, K. M. Cheng, D. J. Bruggers, in Sperm Competition and the Evolution of Animal Mating Systems, R. L. Smith, Ed. (Academic Press, New York, 1984); $\rightarrow$ D. F. Westneat, Amin. Behav. 35, 877 (1987); P. W. Sherman and M. L. Morton, Behav. Ecol. Sociobiol. 22, $413(19 \rightarrow$ T. Burke, N. B. Davies, M. W. Bruford, B. J. Hatchwell, Nature 338, 249 (1989); D. F. Westneat, P. W. Sherman, M. L. Morton, in Current Orrithology, D. Power, Ed. (Plenum, New York, in press), vol.

44. S. T. Emlen, in Behavioural Ecology, An Evolutionary Approach, J. R. Krebs and N B. Davies, Eds. (Blackwcll Scientific, Oxford, 1984), pp. 305-339; J. L. Brown, 
Helping and Communal Breeding in Birds (Princeton Univ. Press, Princeton, NT 1987); P. B. Stacy and W. D. Koenig, Cooperative Breeding in Birds: Long Term Studies of Avian Demography and Behavior (Cambridge Univ. Press, Cambridge, MA, 1989)

45. U.-H. Reyer, Anim. Behav. 32, 1163 (1984); W. D. Koenig and R. L. Mumme Population Ecology of the Cooperatively Breeding Acom Woodpecker (Princeton Univ. Press, Princeton, NJ, 1987).

$\rightarrow$ S. T. Emlen and P. H. Wrege, Behav. Ecol. Sociobiol. 23, 305 (1988); ibid., in press.

47. G. E. Woolfenden and J. W. Fitzpatrick, The Florida Scrub Jay: Demography of a Cooperative-Breedine Bird (Princeton Univ. Press, Princeton, NJ, 1984).

48. M. J. West-Eberhard, Q. Rev. Biol. 50, l (1975).

49. K. Lorenz, J. Ornithol. 83, 137, 289 (1935).

50. N. Tinbergen, The Study of Instinat (Oxford Univ. Press, Oxford, 1951).

51. O. Heinroth, Verh. Int. Ornithol. Kongr. (Berlin) 5, 589 (1911).

52. C. O. Whitman, Publ. Camegie Inst. 257, l (1919).

53. K. Lorenz, J. Ornithol, 89, 194 (1941).

54. A. Kortlandt, Arch. Zool. 4, 401 (1940)

55. N. Tinbergen, Behaviour 15, l (1959).

$\rightarrow$ P. Marler, Nature 176, 6 (1955).

57. Behaviour 11, 13 (1957)

58. S. T. Emlen, ibid 41, 130 (1972); P. H. Becker, in Acoustic Communication in Birds, D. E. Kroodsma and E. H. Miller, Eds. (Academic Press, New York, 1982), vol 1, pp. 214-252.

59. J. S. Weeden and J. B. Falls, Auk 76, 343 (1959); P. C. Mundinger, Science 168 480 (1970); G. Gottlieb, ibid. 147, 1596 (1965); B. Tschanz, Z. Tierpsychol Beih. 4, 1 (1968).

60. P. Marler, in Monkeys and Apes: Field Siudies of Ecology and Behavior, I. DeVore, Ed. (Holt, Rinehart and Winston, New York, 1965), pp. 544-584

61. D. E. Kroodsma and E. H. Miller, Acoustic Communication in Birds (Academic Press, New York, 1982), vol, 2; P. Marler, Trends Neurosii. 4, 88 (1981); M. Konishi, Annu. Rev. Neurosci. 8, 125 (1985)

62. W. H. Thorpe, Bird-Song (Cambridge Univ. Press, New York, 1961).

63. M. Konishi, $Z$. Tierpsychol. 22, 770 (1965).

64. Dolphins can imitate simple sound patterns; see D. G. Richards, J. P. Wolz, L. M. Herman, J. Comp. Psychol. 98, 10 (1984).

65. P. Marler, Am. Sci. 58, 669 (1970).

66. P. K. Kuhl, Human Evol. 3, 19 (1988).

67. K. von Frisch, The Dance Language and Orientation of Bees (Harvard Univ. Press, Cambridge, MA, 1967).

68. A. Hasler, Underwater Guideposts (Univ, of Wisconsin Press, Madison, WI, 1966)

69. 1. R. Griffin, Bird Migration (Doubleday, New York, 1964); G. V. T. Matthews, Bird Navigation (Cambridge Univ. Press, New York, ed. 2, 1968).

70. G. Kramer, Proc. Int. Ornithol. Congr. 10, 269 (1951).

71. E. G. F. Sauer, Z. Tierpsychol. 14, $29(19 \rightarrow$ S. T. Enlen, Auk 84, 309 (1967);

$\rightarrow$ Science 170, $1198(1970)$; F. R. Moore, Nature 275, 154 (1978); K. P. Able, ibid 299, $550(1982)$.

72. W. Wiltschko, Z. Tierpsychol. 25, 537 (1968); ___ and R. Wiltschko, Science $176,62(1972)$

73. S. A. Gauthreaux, Jr., and K. P. Able, Nature 228, 476 (1970); K. P. Able, Anim Behav. 25, $924\left(19^{\prime} \rightarrow\right.$ W. J. Richardson, Oikos 30, 224 (1978).

74. S. T. Emlen, in Avian Biology, D. S. Farner and J. R. King, Eds. (Academic Press Ncw York, 1975), vol. 5, pp. 129-219; K. P. Ablc, in Animal Migration, Orientation, and Navigation, S. A. Gauthreaux, Ed. (Academic Press, New York, 1981), pp. 284-373

75. W. Wiltschko and R. Wiltschko, in Current Omithology, R. F. Johnston, Ed (Plenum, New York, 1988), vol. 5, pp. 67-121

76. W. T. Keeton, Rec. Adv. Behav. 5, 47 (1974).

77. F. Papi, P. Ioale, V. Fiaschi, S. Benvenuti, N. E. Baldaccini, Proc. Int. Omithol Congr. 17, 569 (1980)

78. C. H. Walcott and A. J. Ledner, in Perspectives in Ornithology, A. H. Brush and G. A. Clark, Jr., Eds. (Cambridge Univ. Press, New York, 1983), pp. 513-541.

79. K. Schmidt-Nielsen, Sci. Am. 225, 72 (December 1971).

80. P. Scheid, in Avian Biology, D. S. Farner and J. R. King, Eds. (Academic Press, New York, 1982), vol. 6, pp. 405-453.

81. V. A. Tucker, J. Exp. Biol, 48, 67 (1968).

82. W. R. Dawson and J. W. Hudson, in Comparative Physiology of Thermoregulation, G. Causey Whittow, Ed. (Academic Press, New York, 1970), pp. 224-310; G. A Bartholomew, in Animal Physiology: Principles and Adaptations, M. S. Gordon, Ed. (Macmillan, New York, 1972), pp. 298-365.

83. K. Schmidt-Nielsen, Circulation 21, 955 (1960)

84. G. A. Bartholomew, Proc. Int. Omithol. Congr. 15, 237 (1972).

85. R. E. Ricklefs, Publ. Nuttall Ornithol. Club 15, 152 (1974); T. J. Case, Q. Rev. Biol. 55, 243 (1978); R. H. Drent and S. Daan, Ardea 68, 225 (1980).

$\rightarrow$ R. E. Ricklefs, Biol. Rev. 54, 269 (1979)

87. $\rightarrow-$, Ecology 65, 1602 (1984).

88. R. J. O'Conner, The Growth and Development of Birds (Wiley-Interscience, New York, 1984).

89. R. E. Ricklefs, Avian Biol. 7, l (1983)

90. A. B. Harper, Am. Nat. 128, 99 (1986); D. J. T. Hussell, ibid. 131, 175 (1988)

$\rightarrow$ J. Stamps, A. Clark, P. Arrowood, B. Kus, Behaviour 94, 1 (1985).

91. D. B. Werschkul and J. A. Jackson, Ibis $121,97(19 \rightarrow$ D. W. Mock, Science 225 $731(19 ; \rightarrow$ G. R. Bortolotti, Ecology 67, 182 (1986)

92. J. Balthazart, in Avian Biology, D. S. Farner, J. R. King, K. C. Parkes, Eds.
Academic Press, New York, 1983), vol. 7, pp. 221-365.

$\rightarrow$ C. H. Harding, Am. Zool. 21, 223 (1981).

94. D. S. Lehrman, in Sex and Behavior, F. A. Beach, Ed. (Wiley, New York, 1965), pp. $355-580$.

95. R. A. Hinde, ibid., pp. 381-415.

$\rightarrow$ J. C. Wingfield, Horm. Behav. 19, 174 (1985)

$\rightarrow$ B. Silverin, Anim. Behav. 28, $906(1980) ; J$. Exp. Zool 232, $581(19 \rightarrow$ M. C. Moore, Horm. Behav. 16, 323 (1982); J. C. Wingfield, G. F. Ball, A. F. Dufty, R E. Hegner, M. Ramenofsky, Am. Sci. 75, 602 (1987).

$\rightarrow$ J. C. Wingfield, Auk 101, 665 (1984); R. E. Hegner and J. C. Wingfield, ibid. $104,462(1987)$

99. W. Rowan, Nature 115, 494 (1925).

$1 \rightarrow$ J. R. King and D. S. Farner, Condor 65, 200 (1963); D. S. Farner, J. R. King, M H. Stenton, Prog. Endocrinol. Excerp. Med. Int. Congr. Ser. 184, 152 (1968)

101. D. S. Farner and B. K. Follett, in Hormones and Evolution, E. J. W. Barrington, Ed. (Academic Press, New York, 1979), pp. 829-872.

102. B. K. Follett, P. W. Mattocks, D. S. Farner, Proc. Natl. Acad. Sci. U.S.A. 71 1666 (1974)

103. E. Bünning, Cold Spring Harbor Symp. Quant. Biol. 25, 249 (1960).

104. J. Benoit, C. R. Soc. Biol. 120, 136 (1935).

105. M. Menaker, R. Roberts, J. Elliott, H. Underwood, Proc. Natl. Acad. Sci. U.S.A. $67,320(1970)$

106. K. Yokoyama, A. Oksche, T. R. Darden, D. S. Farner, Cell Tiss. Res. 189, 441 (1978).

107. E. Gwinner, Circannual Rhythms (Springer-Verlag, Berlin, 1986).

108. T. J. Nichols, A. R. Goldsmith, A. Dawson, Physiol. Rev. 68, 133 (1988)

109. J. Benoit and I. Assenmacher, Arch. Anat. Microsc. Morphol. Exp. 42, 334 (1953).

110. A. Oksche and D. S. Farner, Ergeb. Anat. Entwicklungsgesch. 48, 4 (1974)

111. R. P. Millar and J. A. King, J. Exp. Zool. 232, 425 (1984).

112. R. D. Palmiter, E. R. Mulvihill, G. S. McKnight, A. W. Senear, Cold Spring Harbor Symp. Quant. Biol. 42, 639 (1978)

113. B. W. O'Malley, M. R. Sherman, D. O. Toft, Proc. Natl. Acad. Sci. U.S.A. 67, $501(1970)$.

114. J. B. Hutchison and T. Steimer, Science 213, 244 (1981)

115. F. Nottebohm, T. M. Stokes, C. M. Leonard, J Comp. Neurol. 165, 457 (1976)

116. F. Nottebohm, Prog. Psychobiol. Physiol. Psychol. 9, 85 (1980)

117. M. Konishi and E. Akutagawa, Brain Res. 222, 442 (1981).

118. V. Luine, F. Nottebohm, C. Harding, B. McEwen, ibid. 192, 89 (1980); W. V. Bleisch, V. N. Luine, F. Nottebohm, J. Neurosci, 4, 786 (1984)

$1 \rightarrow$ T. J. DeVoogd and F. Nottebohm, Science 214, 202 (1981); F. Nottebohm, Brain Res. 289, $492(1980)$

120. F. Nottebohm, M. E. Nottebohm, L. A. Crane, J. C. Wingfield, Behav. Neural Biol. 47, 197 (1987).

121. F. Nottebohm, Science 214, 1368 (1981)

122. J. R. Kirn, R. P. Clower, D. E. Kroodsma, T. J. DeVoogd, J. Neurobiol. 20, 139 (1989)

123. M. Gahr, J. Comp. Neurol., in press.

124. R. A. Canady, G. D. Burd, T. D. DeVoogd, F. Nottebohm, J. Neurosci. 8, 3770 (1988).

125. F. Nottebohm, in Neural Control of Reproductive Function, J. M. Lakoskin, J. R Perez-Plo, D. K. Rassin, Eds. (Liss, New York, 1989), pp. 583-601.

126. F. Nottebohm and A. P. Arnold, Science 194, 211 (1976).

127. M. Konishi and E. Akutagawa, Nature 315, 145 (1985).

128. S. M. Breedlove and A. P. Arnold, Science $210,564(19 \rightarrow$ R. A Gorski, R. E Harlan, C. D. Jacobson, J. E. Shryne, A. M. Southam, J. Comp. Neurol. 193, 529 $(19 ; \rightarrow$ D. F. Swaab and E. Fliers, Science 228, $1112(1985)$.

129. R. W. Goy and B. S. McEwen, Sexual Differentiation of the Brain (MIT Press, Cambridge, MA, 1980)

130. S. M. Breedlove, J. Neurobiol. 17, $157(198 \rightarrow$ D. Commins and P. Yahr, $J$ Comp. Neurol. 224, 132 (1984).

131. M. E. Gurncy, J. Neurosci. 1, 658 (1981); M. Konishi and E. Akutagawa, Cibo Found. Symp. 126, 173 (1987)

132. S. A. Goldman and F. Nottebohm, Proc. Natl. Acad. Sci. U.S.A. 80, 239 (1983)

$\rightarrow$ J. A. Paton and F. Nottebohm, Science 225, 1046 (1984); A. Alvarez-Buylla, N M. Theelen, F. Nottebohm, Proc. Natl. Acad. Sci. U.S.A. 85, 8722 (1988); A. Alvarez-Buylla and F. Nottebohm, Nature 335,353 (1988)

133. B. M. Ryals and E. W. Rubel, Science 240,1774 (1988)

134. H. J. Karten, Ann. N.Y. Acad. Sai. 167, 164 (1969).

135. R. S. Payne, J. Exp. Biol. 54, 535 (1971).

136. M. Konishi, T. T. Takahashi, H. Wagner, W. E. Sullivan, C. E. Carr, in Auditory Function, G. M. Edelman, W. E. Gall, W. M. Cowan, Eds. (Wiley, New York, 1988), pp. 721-745.

137. S. R. Young and E. W. Rubel, J. Neurosci. 3, 1273 (1983)

138. C. E. Carr and M. Konishi, Proc. Natl. Acad. Sci. U.S.A. 85, 8311 (1988)

139. J. M. Goldberg and P. B. Brown, J. Neurophysiol, 32, 613 (1969).

140. E. I. Knudsen and M. Konishi, Science 200, 795 (1978).

141. M. Konishi, Trends. Neurosci. 9, 163 (1986); E. I. Knudsen, S. du Lac, S. D. Esterly, Annu. Rev. Neurosci. 10,4l (1987).

142. J. C. Middlebrooks and E. I. Knudsen, J. Neurosci. 4, 2621 (1984).

143. E. I. Knudsen, ibid. 2, 1177 (1982); E. I. Knudsen and P. H. Knudsen, J Comp. Neurol. 218, 187 (1983).

144. We thank P. Marler, G. H. Orians, and S. F. Volman for critically reading an early draft of the paper. This work was supported in part by NSF grants BNS 85 17725 to S.T.E. and DCB 8616189 to J.C.W. 